\title{
The Impact of COVID-19 Pandemic on the Financial Contagion among Turkey, US, and China Stock Markets
}

\section{Ecenur UĞURLU YILDIRIM ${ }^{\text {iD a }}$}

a Social Sciences University of Ankara, Department of Business Administration, Ankara, Turkey. ecenur.yildirim@asbu.edu.tr

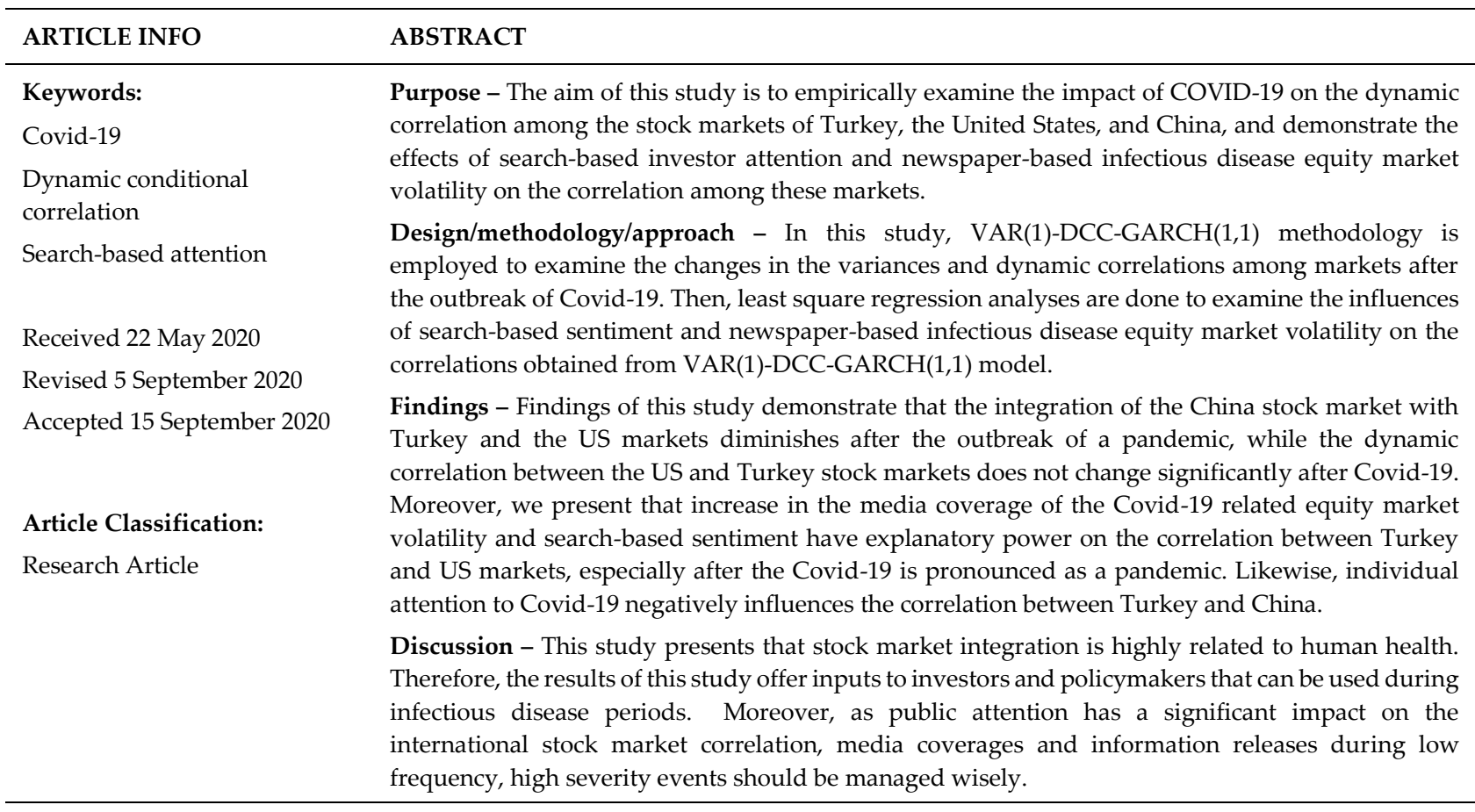

\section{Introduction}

COVID-19 has a damaging impact not only on the healthcare system but also on the global economy and financial markets since its first known outbreak at the end of 2019. This pandemic is considered as the most powerful infectious disease in history in terms of the influences on the stock markets in all around the world. As an example, the volatility levels in the Unites States' (US) stock markets exceeds or catch the volatilities seen in late 1929, the 1930s, October 1987, and the final financial crisis in December 2008. One of the potential explanations of this powerful impact of Covid-19 on stock markets is the huge impact of this pandemic on the economy. Second, the increase in the amount of information and the easiness to access this information during this pandemic relative to previous pandemics and crises make the consequences of Covid-19 more severe relative to previous crises. Finally, the interconnectedness of the economies has been increased in the last century (Baker et al., 2020:6). This study aims to contribute this literature by examining the effects of Covid-19 on the dynamic correlation among Turkey, US, and China, and whether the correlation among these markets is influenced by the investors' attention on Covid-19 and daily infectious disease equity market volatility index (EMV) constructed by Baker et al. (2020).

As globalization has increased in the last decades, studies on the correlations among the countries' risks, performances of the stock markets, and global factors gather a huge amount of interest (see Kocaarslan et al., 2018:541-74; and Abad et al., 2010:2851-60). However, the number of studies on the impacts of epidemic or

\section{$\underline{\text { Suggested Citation }}$}

Uğurlu Yıldırım, E. (2020). The Impact of COVID-19 Pandemic on the Financial Contagion among Turkey, US, and China Stock Markets, Journal of Business Research-Turk, 12 (3), 2764-2773. 


\section{E. Uğurlu Yıldırım 12/3 (2020) 2764-2773}

pandemic diseases on the stock market integration is still scant (Chen et al., 2018:909). By examining the impact of Covid-19 on the integration of the Turkey stock market with the stock markets of China and the US, which are the starting point of the pandemic and the most affected country, respectively, we aim to demonstrate the relation between stock market integration and human health by utilizing VAR(1)-DCC-GARCH(1,1) methodology.

Our paper also contributes to the literature by demonstrating the impacts of people's attention to unanticipated catastrophic events, and newspaper-based infectious disease EMV on the dynamic correlations between markets. In this way, we aim to demonstrate whether the low-frequency high severity events, such as pandemics, alter the correlation among markets by influencing the search-based and newspaper-based public attention on infectious diseases.

The rest of this paper is organized as follows. Existent literature is discussed in Section 2. Section 3 demonstrates the data and methodology used in empirical analyses. Our findings are presented in Section 4. Finally, Section 5 gives the concluding remarks.

\section{Literature Review}

Epidemics and pandemics, in general, are sudden unanticipated events which are expected to have impacts on the general economy, money markets, and stock markets (Talib, 2007:2; Ngwakwe, 2020:1). However, there is no consensus on the effects of such incidents. Keating (2001) demonstrates that reactions of the stock markets are generally cyclical to these unexpected events. By exploring the impact of the severe acute respiratory syndrome (SARS) on the Taiwanese economy, Chen et al. (2007) demonstrate that epidemics influence economies negatively. On the other hand, other studies, including Nippani and Washer (2004), claim SARS did not have a significant impact on the stock markets apart from a few countries.

With the increase in globalization, the integrations of the financial markets are also enhanced. As epidemics and pandemics are considered as low-frequency high severity events (Dowd, 2007), they are expected to affect the financial markets integration all around the world. To this extent, studies examine the effects of infectious diseases on the financial markets integration. Theoretically, the efficient market hypothesis and asset pricing theory claim that diversifiable risk does not provide an additional reward when systematic economic information affects specific assets. Therefore, epidemics, such as SARS, or pandemics, such as Covid-19, are expected to be strongly related to market integration (see Merton, 1973; Chen et al., 1986:383-403; Chen et al., 2018:909). Contrarily, by influencing risk aversion of investors positively, infectious diseases might result in the money withdrawal from the disease-origin or influenced markets. This results in the reduction of the integration level of these markets with the others (Chen et al., 2018:908). Empirical studies also reveal mixed results. Onay and Ünal (2012) show, even after epidemics, diversification is still possible in extremes of the markets. Likewise, Chen et al. (2018) demonstrate that infectious diseases influence stock market integration negatively among countries in the same regional economic block by examining the long-run link between China and the other five Asian stock markets before and after the SARS. On the other hand, some other studies demonstrate that the impacts of the infectious diseases on the market integrations depend on whether the market is bearish or bullish. While the low-frequency high severity events increase the correlations in the former one, there is no significant impact on the latter one (Longin and Solnik, 2001). This study aims to shed more light on this literature by exploring the impact of Covid19 on the integration of Turkey stock market with the disease-sourcing country, China, and the most infected market, the US.

Secondly, this study is related to the literature on the link between asset prices and investor sentiment. Although the relation among them has been studied widely in the literature in the last decades (see Bekaert et al., 2019; Baker and Wurgler, 2007), the number of studies on internet search-based sentiment is relatively scarce. Google search is employed as a direct indicator of investor attention in Da et al. (2011) that present stocks generate higher prices in the following two weeks with the increase in the Google search amount of the related company. Internet searches are considered as a channel that investors show their information requirement (Drake et al., 2012), and employing this indicator as a sentiment measure is preferable than its alternatives because of its higher transparency (see Da et al., 2015, Papadamou et al., 2020) Moreover, studies demonstrate that implied volatility of 


\section{E. Uğurlu Yıldırım 12/3 (2020) 2764-2773}

stock is significantly directly associated with the attention of investors (see Ruan and Zhang, 2016; Vlastakis and Markellos, 2012). Recently, by employing panel-data analysis, Papadamou et al. (2020) explore whether the attention of investors to Covid-19 influences countries' stock market indices returns and whether the risk-aversion in stock markets is affected from the Covid-19. Their results indicate that Google-based anxiety about the impacts of this novel Coronavirus enhances the risk-aversion of the investors in stock markets. We aim to contribute these studies by exploring the impact of the search-based sentiment of investors in Turkey on the Turkey stock market integration with the stock markets of the US and China.

Finally, this paper examines whether the dynamic correlation between Turkey stock market returns, and the US and China returns are influenced by the newspaper-based infectious disease equity market volatility (EMV) in the US constructed by Baker et al. (2020). Although there are several infectious diseases in the last century, none of them had such a huge impact on the stock market volatilities. Even the Spanish Flu from 1918 to 1920, which slew approximately two percent of the population of the world, did not cause big daily moves in the market (see Baker et al., 2020:3; Barro et al., 2020). By examining the effect of newspaper-based infectious disease EMV on the correlation between markets, we aim to explore the impact of public attention on infectious diseases and the stock market on market integration.

\section{Data and Methodology}

\subsection{Data}

Our sample period is between January 01, 2015 and May 05, 2020 including pre-pandemics and post-pandemics periods. Since the Covid-19 outbreaks in late 2019 in China than spreads all over the world through 2020, while the pre-pandemics subsample contains data from January 01, 2015 to November 30, 2019, the post-pandemics period contains data from January 01, 2020 to May 05, 2020. We employ daily closing prices of the Turkey, US, and China stock market to obtain daily returns, hereafter BIST100, SP100, and SSE100. Data are obtained from the webpage of Investing.

As a newspaper-based infectious disease equity market volatility in the US, hereafter COVID, we employ the tracker that is constructed by Baker et al. (2020). By detecting the EMV articles in daily newspapers, which contain infectious disease terms like COVID-19, and multiplying this portion of articles with their EMV tracker, they obtain "Infectious disease EMV tracker" (Baker et al., 2020:1). The daily changes in this variable can be considered as public attention on infectious diseases and stock markets.

Another public attention indicator used in this study, hereafter GOOGLE, is proxied by the daily changes in the amount of the "Covid-19" term searching in Google in Turkey for the sample period. This variable provides the search-based sentiment of the individuals (Papadamou et al., 2020)

GARCH models are employed to obtain conditional variances.

Unit-root tests results of the variables in interest are given in Table 1. Augmented Dickey-Fuller (1979), ADF, and Generalized Least Squares- Dickey Fuller,GLS-DF, tests are employed to get the stationarity characteristics of the variables in interest. Except for COVID and GOOGLE, all variables are stationarity. In OLS tests, daily changes in COVID and GOOGLE are used.

In Figure 1, the returns of the equity market indices for the sample period is demonstrated. Due to observed heteroscedasticity and volatility clustering, GARCH models are employed to investigate the dynamic conditional correlations between the stock markets (see Kocaarslan et al., 2018:541-74). 


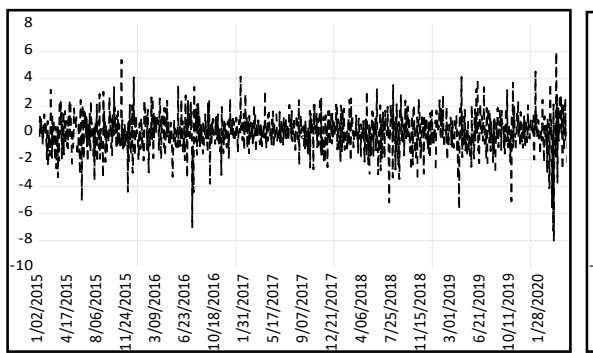

a) BIS100

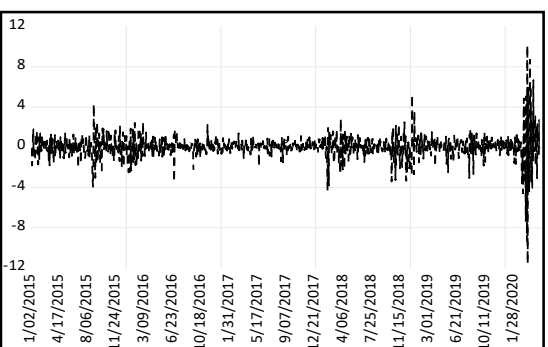

b)SP100

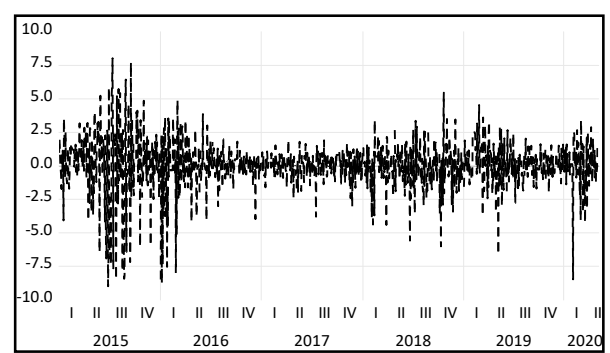

c) SSE100

Figure 1. Daily market returns during the sample period

Table 1. Unit-root test results

\begin{tabular}{lcccccccc}
\hline & \multicolumn{3}{c}{ ADF } & \multicolumn{3}{c}{ DF-GLS } \\
\hline & \multicolumn{2}{c}{ Int. } & \multicolumn{2}{c}{ Int. \& Trend } & \multicolumn{2}{c}{ Int. } & \multicolumn{2}{c}{ Int. \& Trend } \\
\hline Stat. & Lag & Stat. & Lag & Stat. & Lag & Stat. & Lag \\
\hline Panel A: Levels & & & & & & & & \\
\hline BIST100 & $-9.433^{* * *}$ & 0 & $-9.379^{* * *}$ & 0 & $-4.239^{* * *}$ & 1 & $-4.858^{* * *}$ & 1 \\
SP100 & $-15.106^{* * *}$ & 0 & $-15.101^{* * *}$ & 0 & $-3.670^{* * *}$ & 2 & $-14.775^{* * *}$ & 0 \\
SSE100 & $-9.750^{* * *}$ & 0 & $-9.691^{* * *}$ & 0 & $-8.404^{* * *}$ & 0 & $-9.352^{* * *}$ & 0 \\
COVID & -1.215 & 2 & $-3.170^{*}$ & 0 & -0.692 & 2 & $-3.157^{* *}$ & 0 \\
GOOGLE & -2.175 & 0 & -2.092 & 0 & $-1.711^{*}$ & 0 & -2.165 & 0 \\
\hline Panel B: First Differences & & & & & & & 0 \\
\hline BIST100 & $-11.017^{* * *}$ & 1 & $-10.965^{* * *}$ & 1 & -0.948 & 6 & $-14.976^{* * *}$ & 0 \\
SP100 & $-7.371^{* * *}$ & 0 & $-7.332^{* * *}$ & 0 & -1.475 & 6 & $-12.968^{* * *}$ & 1 \\
SSE100 & $-10.874^{* * *}$ & 1 & $-10.809^{* * *}$ & 1 & $-13.053^{* * *}$ & 0 & $-15.496^{* * *}$ & 0 \\
COVID & $-9.269^{* * *}$ & 1 & $-9.201^{* * *}$ & 1 & $-9.271^{* * *}$ & 1 & $-11.256^{* * *}$ & 0 \\
GOOGLE & $-9.851^{* * *}$ & 0 & $-9.857^{* * *}$ & 0 & $-9.904^{* * *}$ & 0 & $-9.953^{* * *}$ & 0 \\
\hline
\end{tabular}

Notes: Unit-root tests results for levels and first-differences are presented in Table 1. BIST100, SP100, SPE100, COVID, and GOOGLE refer to daily returns on BIST100 index, daily returns on SPE100 index daily returns on SSE100 index, infectious disease EMV, and search-based individual attention for Covid-19, respectively. Augmented Dickey Fuller, and Dickey-Fuller GLS detrended denoted as ADF and DF-GLS, respectively. Schwarz Information Criterion (SIC) is used automatically to determine lag lengths. Superscripts ***, **, and * demonstrate 1\%, 5\%, and 10\% significance, respectively. Int. refers intercept, and int. \& trend refers to intercept and trend.

\subsection{Methodology}

In this study, VAR-DCC-GARCH(1,1) methodology is employed in order to examine the dynamic correlations between the stock markets of Turkey, US, and China. To consider the non-synchronous trading and serial correlations, a vector autoregressive (VAR) context is utilized (Forbes and Rigobon, 2002). Based on Schwarz Information criterion (SCI) and Hannan-Quinn information criterion, VAR(1) specifications is chosen in our analyses. In the first step, the linear relationship between markets, mean equation demonstrated in equation 1 , is assessed;

$$
Y_{t}=\vartheta_{0}+\sum_{i=1}^{n} \vartheta_{i} Y_{t-i}+\epsilon_{t}
$$

where $\mathrm{Y}_{\mathrm{t}}$ is vector including Turkey, US, and China stock market returns.

Then, 


\section{E. Uğurlu Yıldırım 12/3 (2020) 2764-2773}

$$
h_{t}=\mu_{0}+\sum_{i=1}^{p} \mu_{i} \varepsilon_{t-1}^{2}+\sum_{j=1}^{q} \rho_{j} h_{t-j}
$$

where the constant parameters are shown by $\mu_{0}, \mu_{i}$, and $\rho_{j} . \mu_{0}, \mu_{1}$, and $\rho_{1}$ are non-negative and $\mu_{1}+\rho_{1}<1$, which result with non-negative variances (see Bollerslev, 1986; and Gokcan, 2000).

In order to get the residuals, GARCH $(1,1)$ model is used. To get the correlation parameters. Equation 3 gives the DCC-GARCH model's correlations development.

$$
\begin{aligned}
& Q_{t}=(1-x-y) \bar{\theta}+x\left(\epsilon_{t-1} \epsilon_{t-1}^{\prime}\right)+y\left(Q_{t-1}\right) \\
& \theta_{t}=Q_{t}^{*-1} Q_{t} Q_{t}^{*-1}
\end{aligned}
$$

in which $\mathrm{x}$ and $\mathrm{y}$ are scalers that $\mathrm{x}+\mathrm{y}<1$, and $\bar{\theta}=E\left[\epsilon_{T} \epsilon_{T}^{\prime}\right] . Q_{t}^{*}$ indicates a diagonal matrix that on its $\mathrm{i}^{\text {th }}$ diagonal place, there is the square root of $Q^{\prime}{ }^{\prime} i^{\text {th }}$ diagonal element (see Engle, 2002; Kocaarslan et al., 2018: 541-74).

In the final step of our analyses, we investigate whether the dynamic correlations of the Turkey stock market with the US and China after the outbreak of Covid-19 are influenced by the search-based sentiment, GOOGLE, and newspaper-based infectious disease EMV, COVID. In order to do so, least square (LS) estimation of the following equation is analyzed;

$$
Q_{(t)}=\alpha_{t}+\beta_{1 t} D G O O G L E_{t}+\beta_{2 t} D C O V I D_{t}+\varepsilon_{t}
$$

where the dependent variable is the first-differences of the series of time-varying conditional correlation derived from DCC model, $\beta^{\prime}$ s are the influences of explanatory variables on the stock markets' co-movements after the outbreak of Covid-19. DGOOGLE and DCOVID are the first-differences of the search-based attention and infectious disease EMV, respectively.

\section{Empirical findings}

The results of the mean equation shown in equation 1, which is the first step of our analyses, are shown in Table 2 for the sample periods before and after the Covid-19 outbreak. It can be seen that US lag returns predict both Turkey and China returns. Turkey's returns are also affected by the returns of China before Covid-19 outbreak; however, the influence of China returns on Turkey stock returns becomes insignificant after the pandemic. Moreover, the significance of the influence of China stock market returns on the US returns diminishes after the Covid-19. Returns on China stocks are only affected by US stock returns, and the significance of this influence also decreases after the pandemic.

Table 2. Results of the mean equation

Independent Variables

\begin{tabular}{ccccc} 
Dependent Variable & Constant & BIST100(-1) & SP100(-1) & SSE100(-1) \\
\cline { 2 - 5 } & \multicolumn{5}{c}{ Panel A: Entire sample period } \\
\hline BIST100 & 0.048 & -0.010 & $0.141^{* * *}$ & $-0.034^{*}$ \\
SP100 & $0.085^{* * *}$ & -0.003 & -0.023 & $-0.019^{* *}$ \\
SSE100 & 0.032 & 0.009 & $0.264^{* * *}$ & 0.024 \\
\hline \multicolumn{5}{c}{ Panel B: After Covid-19 outbreak } \\
\hline BIST100 & -0.001 & -0.059 & $0.154^{*}$ & -0.147 \\
SP100 & $0.317^{* *}$ & -0.68 & -0.225 & $-0.133^{*}$ \\
SSE100 & 0.164 & 0.117 & $0.102^{* *}$ & 0.004 \\
\hline
\end{tabular}

Notes: Mean equation results are presented in Table 2. BIST100, SP100, and SPE100 refer to daily returns on BIST100 index, daily returns on SPE100 index, and daily returns on SSE100 index, respectively. Superscripts ${ }^{* * *}$, **, and * demonstrate $1 \%, 5 \%$, and $10 \%$ significance, respectively. 
Table 3 presents the findings of the variance equation obtained from univariate GARCH $(1,1)$ models. $\chi$ and $\beta \mathrm{h}$ represent $\mathrm{ARCH}$ and $\mathrm{GARCH}$ parameter, respectively. Almost all of the ARCH-GARCH parameters are statistically significant, which indicates the existence of conditional heteroscedasticity. Furthermore, results imply the substantial impact of long-run volatility before Covid-19 since the short-run ARCH parameters are smaller than the GARCH parameters. However, after the outbreak of the pandemic, results indicate a substantial effect of short-run volatility for the US and China stock markets, as ARCH parameters are higher than the GARCH parameters for the models in which these markets are employed as dependent variables.

Table 3. Results of the variance equation

\begin{tabular}{clccc}
\hline Market Returns & Model & $\beta_{0}$ & $\chi$ & $\beta_{\mathrm{h}}$ \\
\hline \multicolumn{5}{c}{ Panel A: Entire Sample Period } \\
BIST100 & GARCH $(1,1)$ & $0.050^{* * *}$ & $0.033^{* * *}$ & $0.937^{* * *}$ \\
SP100 & GARCH $(1,1)$ & $0.041^{* * *}$ & $0.216^{* * *}$ & $0.737^{* * *}$ \\
SSE100 & GARCH(1,1) & $0.016^{* * *}$ & $0.061^{* * *}$ & $0.933^{* * *}$ \\
\hline \multicolumn{6}{c}{ Panel B: After Covid-19 outbreak } \\
BIST100 & GARCH(1,1) & 0.229 & $0.199^{* *}$ & $0.760^{* * *}$ \\
SP100 & GARCH(1,1) & 0.072 & $0.604^{* * *}$ & $0.502^{* *}$ \\
SSE100 & GARCH(1,1) & $1.244^{* *}$ & $0.526^{* * *}$ & 0.057 \\
\hline
\end{tabular}

Notes: Variance equation results for the GARCH(1,1) models are presented in Table 3. BIST100, SP100, and SPE100 refer to daily returns on BIST100 index, daily returns on SPE100 index, and daily returns on SSE100 index, respectively. Superscripts ${ }^{* * *}, * *$, and ${ }^{*}$ demonstrate $1 \%, 5 \%$, and $10 \%$ significance, respectively. ARCH and GARCH parameters are shown by $\chi$ and $\beta \mathrm{h}$, respectively.

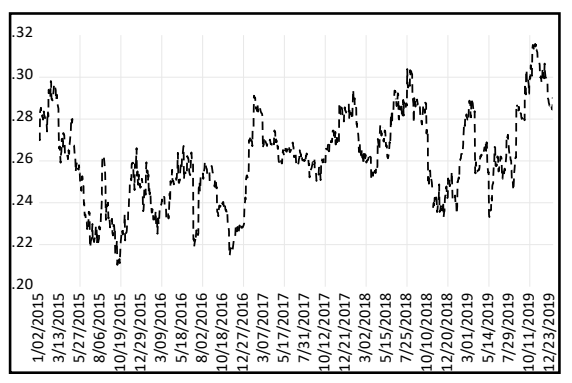

a) BIST100-SP100

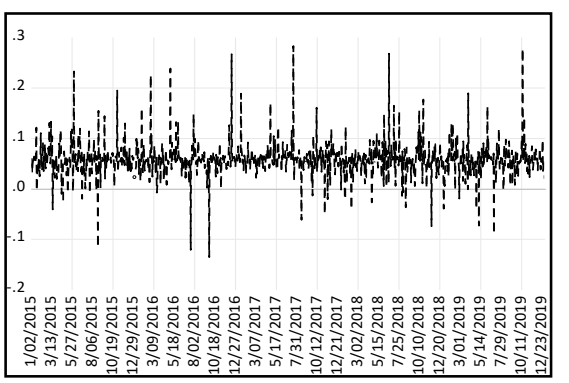

b) BIST100-SSE100

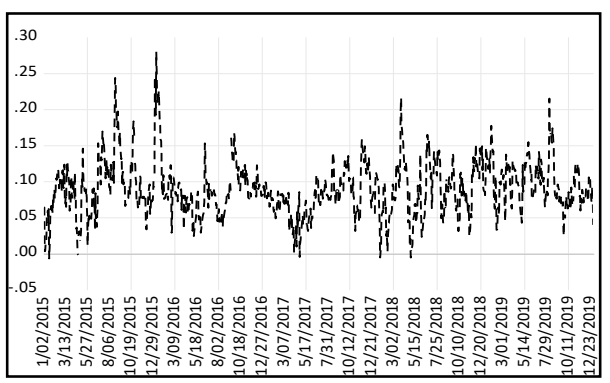

c) SP100-SSE100

Figure 2. Dynamic conditional correlation (DCC) series graphs- Before Covid-19 outbreak

Notes: Dynamic correlaton series are obtained from the DCC model. Graph $a, b$, and c represent correlations between BIST100 and SP100, BIST100 and SSE100, and SP100 and SSE100, respectively.

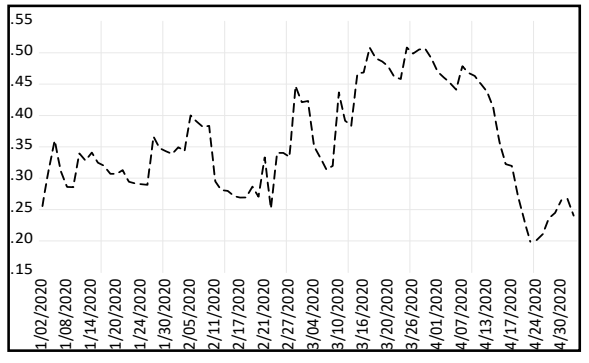

a) BIST100-SP100

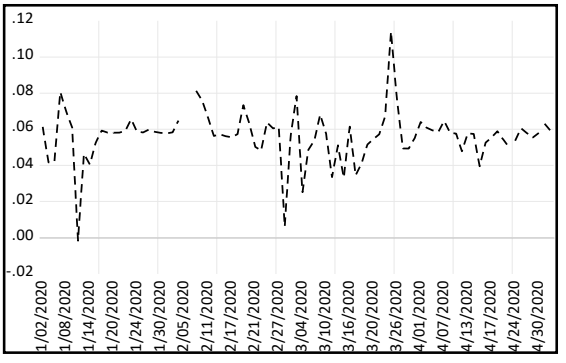

b)BIST100-SSE100

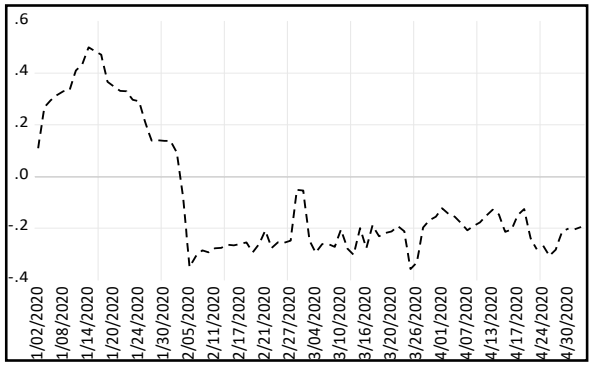

c) SP100-SSE100

Figure 3. Dynamic conditional correlation (DCC) series graphs- After Covid-19 outbreak

Notes: Dynamic correlaton series are obtained from the DCC model. Graph $a, b$, and c represent correlations between BIST100 and SP100, BIST100 and SSE100, and SP100 and SSE100, respectively. 
In the next step, the standardized residuals are obtained from the univariate GARCH models, and the dynamic conditional correlations between markets are derived by employing DCC-GARCH methodology. Figure 2 and Figure 3 present the dynamic correlations between markets for the sample periods before and after the pandemic, respectively. Figure 2 presents that, Turkey stock market shows greater co-movements with US stock market compared to China stock market. Mostly low, sometimes even negative dynamic correlations between China and Turkey indicate that there was room for diversification between these two markets before the outbreak of Covid19. The persistence of low correlations between these two markets suggests the ongoing opportunity to diversify between these two markets after the pandemic. Additionally, the dynamic correlation of the returns between US and China becomes negative after February. This supports Chen et al. (2018), who demonstrate epidemics reduce integration between markets. On the other hand, the dynamic correlations between the US and Turkey present a similar pattern before and after the pandemics, which resonates well with the literature that claims the integrations of the bull markets are not significantly influenced by the low-frequency high severity events (Longin and Solnik, 2001).

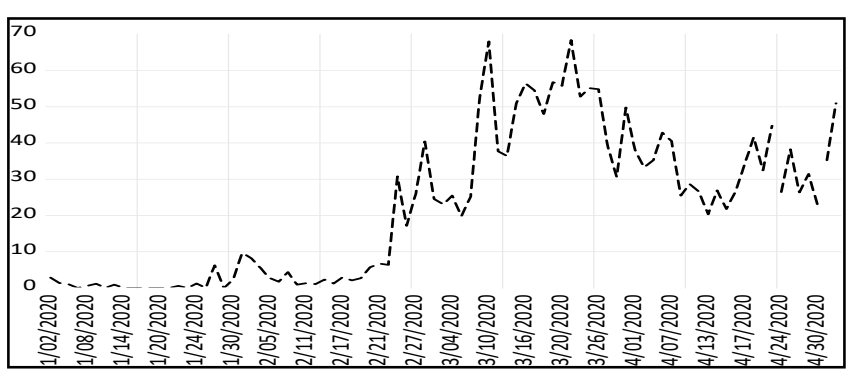

a)Infectious disease EMV

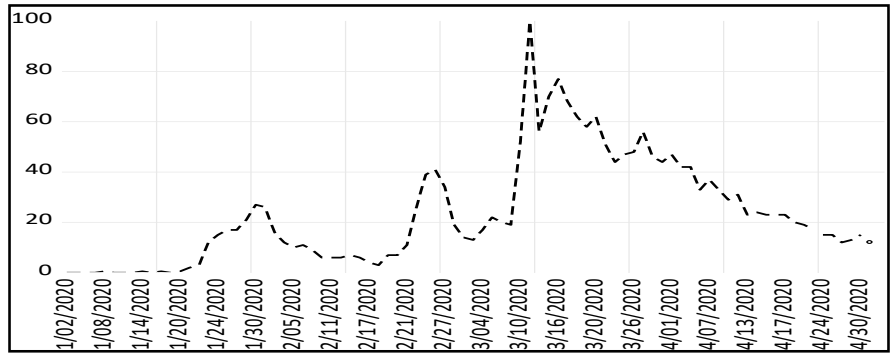

b) Covid-19 attention in Turkey

Figure 4. Independent variables in OLS regressions

Notes: Graphs a and b demonstrate the evolution of the infectious disease EMV tracker and search-based Covid-19 attention in Turkey, respectively.

Table 4. Regression analyses of the impact of COVID and GOOGLE on the dynamic correlation of the Turkey market with US and China markets

\begin{tabular}{|c|c|c|c|c|}
\hline \multirow{2}{*}{ Dependent Variable } & \multicolumn{3}{|c|}{ Independent Variables } & \multirow{2}{*}{$\mathrm{R}^{2}$} \\
\hline & Constant & DGOOGLE & DCOVID & \\
\hline \multicolumn{5}{|c|}{ Panel A: Sample period between January 1, 2020 and May 5, 2020} \\
\hline DCC between TR-US & -0.0004 & 0.0004 & $0.001^{* * *}$ & 0.092 \\
\hline DCC between TR-CHN & 0.0001 & -0.0004 & -0.0002 & 0.003 \\
\hline \multicolumn{5}{|c|}{ Panel B: Sample period between March 11, 2020 and May 5, 2020} \\
\hline DCC between TR-US & -0.0012 & $0.001^{*}$ & $0.001^{*}$ & 0.140 \\
\hline DCC between TR-CHN & 0.0001 & $-0.0003^{*}$ & 0.0002 & 0.146 \\
\hline \multicolumn{5}{|c|}{$\begin{array}{l}\text { Notes: Least Square estimation results are presented in Table 4. TR, US, and CHN refer to Turkey, United States and China, } \\
\text { respectively. DCC indicates a dynamic conditional correlation. DGOOGLE and DCOVID show the first-differences of the } \\
\text { google search volume of the Covid-19 related terms and infectious disease EMV tracker, respectively. Superscripts ***,**, and } \\
* \text { demonstrate } 1 \%, 5 \% \text {, and } 10 \% \text { significance, respectively. ARCH and GARCH parameters are shown by } \chi \text { and } \beta_{h} \text {, } \\
\text { respectively. }\end{array}$} \\
\hline
\end{tabular}




\section{E. Uğurlu Yıldırım 12/3 (2020) 2764-2773}

Finally, Table 4 presents the results of the regression analyses of the impact of investor attention and newspaperbased infectious disease EMV on correlations between BIST100 and other markets. While the relationships between independent variables and dynamic correlations for the period between January 1, 2020 and May 5, 2020 are demonstrated in Panel A, Panel B shows the relationships for the period after the March 11, 2020, which is the day that World Health Organization (WHO) announces Covid-19 as pandemic (Cheng and Yen, 2020). Figure 4 shows the independent variables, GOOGLE and COVID-19, patterns through time. As can be seen from the graph, both of the variables have an increasing trend from the beginning of January to the end of March, then start decreasing. Especially search-based sentiment variable indicates that people's attention to Covid-19 in Turkey almost vanished till the end of April.

Results indicate that the infectious disease EMV has a significant direct impact on the dynamic correlation between Turkey and US markets. An increase in the media coverage of the Covid-19 related EMV increases the integration between Turkey and US markets. This finding supports the literature that states infectious diseases are anticipated to be strongly related to market integration (see Merton, 1973; Chen et al., 1986:384). Moreover, although the Turkish investors' search-based sentiment, proxied by the google-search volume of Covid-19, does not have a significant effect on the correlations neither between Turkey and US stock markets nor between Turkey and China stock markets for the period between January 1st, 2020 and May $5^{\text {th }}, 2020$, search-based attention of investors influences the correlations between markets significantly after the Covid-19 is announced as a pandemic by WHO. However, while this impact is positive for the correlation between the US and Turkey, it is negative for the correlation between China and Turkey. This finding implies that the search-based attention of Covid-19 increases the risk aversion of people investing in China stock market after the declaration of Covid-19 as a pandemic, which results in the withdrawal of money from the disease origin market, China. As a result, the integration between Turkey and China stock markets decreases (Chen et al., 2018:908). Furthermore, our finding supports the volatility feedback hypothesis as the raise in the searching for the effects of Covid-19 results with the rise in the anxiety level of people, which increases the negative link between sock markets and their volatility (see Papadamou et al., 2020).

\section{Discussion and Conclusion}

The outbreak of the pandemics, which are an exogenous shock, have very severe outcomes as increasing public fear and initiating economic uncertainty. This might alter the risk-preferences and asset-allocations of investors, which leads to a change in the integration levels of markets (Ortmann et al., 2020; Wang and Young, 2020; Levy and Galili, 2006). This study aims to examine the impacts of the Covid-19 outbreak on the dynamic correlations between Turkey, the US, and China stock market returns by employing VAR(1)-DCC-GARCH(1,1) methodology. Moreover, the impacts of newspaper-based infectious disease EMV and the search-based sentiment of individuals on the dynamic correlations of the Turkey stock market with the US and China markets after the pandemic are explored.

Our findings can be summarized as follows. First of all, the impact of China stock market on the US and Turkey stock market reduces and becomes insignificant after Covid-19, respectively. This finding resonates well with Chen et al. (2018) that show infectious diseases diminish the market integrations. Second of all, variance equation results demonstrate that pandemic has a substantial impact on short-run volatility for the US and China stock markets. For the Turkey stock market, findings imply a substantial effect of long-run volatility both before and after the outbreak of Covid-19. Third, our results show that Turkey is more correlated with the US stock market than the China market before and after the Covid-19 outbreak. Although the pandemic does not influence the correlation between US and Turkey stock market, the dynamic correlation between US and China stock markets become negative after February, which is in line with Chen et al. (2018) that state infectious diseases increase the risk aversion of investors, which results with the withdrawal of money from disease origin markets and reduce market integration. Finally, in order to test whether the search-based attention and newspaper-based infectious disease EMV influence the dynamic correlation between markets, regression analyses are employed. Our findings suggest that an increase in the media coverage of the Covid-19 related equity market volatility and search-based sentiment have explanatory power on the correlation between Turkey and US markets, especially after the Covid19 is announced as a pandemic. Furthermore, individual attention on Covid-19 significantly negatively affects the 


\section{E. Uğurlu Yıldırım 12/3 (2020) 2764-2773}

correlation between Turkey and China stock market returns after Covid-19 is declared as a pandemic, which supports the extant literature (Chen et al., 2018:909; Papadamou et al., 2020)

Stock market integration, which is important for investors in their portfolio diversification and asset allocation choices, is one of the most focal issues in finance literature. Impacts of the current pandemic, Covid-19, on the countries' economies and financial markets are also the center of another hot debate in the literature. Our findings shed more light on these topics by exploring the effects of Covid-19 on the dynamic correlation of the Turkey stock market with the US and China stock markets, and show that international stock market integration is highly linked to the human health.

On the behavioral aspect, it is shown that risk aversion of the investors increases during infectious disease periods, which diminishes the integration between markets. Especially, as the markets of the disease originated countries are highly influenced by the epidemics, it can be inferred that the investors in these markets become more riskaverse than the others. Moreover, we show the importance of public attention on the level of stock market correlation between countries. Our findings indicate that during low-frequency high severity events like pandemics, media coverages and information releases should be managed sensibly in order to prevent the undesirable outcomes of the public attention on the international market integrations. To that extent, this study provides inputs to investors and policymakers in managing the effects of the pandemic on the financial markets.

\section{References}

Abad, P., Chuliá, H., and Gómez-Puig, M. (2010). EMU and European government bond market integration, Journal of Banking and Finance, 34, 2851-2860.

Baker, S. R., Bloom, N., Davis, S. J., Kost, K. J., Sammon, M. C., and Viratyosin, T. (2020). The unprecedented stock market impact of Covid-19, National Bureau of Economic Research Working paper No. w26945.

Baker, M., and Wurgler, J. (2007). Investor sentiment in the stock market, Journal of Economic Perspectives, 21(2), 129-152.

Barro, R. J., Ursua, J. F., and Weng, J. (2020). The Coronavirus and the great influenza pandemic: Lessons from the Spanish Flu for the coronavirus's potential effects on mortality and economic activity, CESifo Working Paper, No. 8166.

Bekaert, G., Engstrom, E. C., and Xu, N. R. (2019). The time variation in risk appetite and uncertainty, National Bureau of Economic Research Working Paper, No. w25673.

Bollerslev, T. (1986). Generalized autoregressive conditional heteroskedasticity, Journal of Econometrics, 31, 307327.

Chen, M. H., Jang, S. S., and Kim, W. G. (2007). The impact of the S.A.R.S. outbreak on Taiwanese hotel stock performance: An event-study approach, International Journal of Hospitality Management, 26(1), 200-212.

Chen, M. P.; Lee, C. C.; Lin, Y. H. and Chen, W. Y. (2018). Did the SARS epidemic weaken the integration of Asian stock markets? Evidence from smooth time-varying cointegration analysis, Economic research, 31(1), 908926.

Chen, N. F., Roll, R., \& Ross, S. A. (1986). Economic forces and the stock market, The Journal of Business, 59(3), 383403.

Cheng, H. P., and Yen, K. C. (2020). Does Covid-19 affect the financial market?, SSRN Working Paper, No.3578263.

Da, Z., Engelberg, J., and Gao, P. (2011). In search of attention, The Journal of Finance, 66(5), 1461-1499.

Da, Z., Engelberg, J., and Gao, P. (2015). The sum of all FEARS investor sentiment and asset prices, The Review of Financial Studies, 28(1), 1-32.

Dickey, A. D., and Fuller, W. A. (1979). Distribution of the estimators for autoregressive time series with a unit root, Journal of the American Statistical Association, 74, 427-431. 


\section{E. Uğurlu Yildırım 12/3 (2020) 2764-2773}

Drake, M. S., Roulstone, D. T., and Thornock, J. R. (2012). Investor information demand: Evidence from Google searches around earnings announcements, Journal of Accounting Research, 50(4), 1001-1040.

Dowd, K. (2007). Measuring market risk, New York, John Wiley \& Sons.

Engle, R. (2002). Dynamic Conditional Correlation - a Simple Class of Multivariate GARCH Models, Journal of Business and Economic Statistics, 20, 339-50.

Forbes, K. J., and R. Rigobon (2002). No contagion, only interdependence: Measuring stock market co-movements., The Journal of Finance, 57, 2223-2261.

Gokcan, S. (2000). Forecasting volatility of emerging stock markets: Linear versus non-linear GARCH models, Journal of Forecasting, 19, 499-504.

Keating, J. (2001). An investigation into the cyclical incidence of dengue fever, Social science and medicine, 53(12), 1587-1597.

Kocaarslan, B., Soytas, U., Sari, R., and Ugurlu, E. (2018). The changing role of financial stress, oil price, and gold price in financial contagion among US and BRIC markets, International Reviews of Finance, 19(3), 541-574.

Levy, O., and Galili, I. (2006). Terror and trade of individual investors, The Journal of Socio-Economics, 35, 980 - 991.

Longin, F., \& Solnik, B. (2001). Extreme correlation of international equity market, The Journal of Finance, 56(2), 649-676.

Merton, R. C. (1973). An intertemporal capital asset pricing model, Econometrica: Journal of the Econometric Society, 41(5), 867-887.

Nippani, S., \& Washer, K. M. (2004). S.A.R.S.: A non-event for affected countries' stock markets?, Applied Financial Economics, 14(15), 1105-1110.

Ngwakwe, C. C. (2020). Effect of Covid-2019 pandemic on global stock market value: A differential analysis, Economica, 16(2), 261-275.

Ortmann, R., Pelster, M., and Wengerek, S. T. (2020). Covid-19 and investor behavior, TAF Working Paper, No. 54.

Papadamou, S., Athanasios, F., Kenourgios, D., and Dimitriou, D. (2020). Direct and indirect effects of Covid-19 pandemic on implied stock market volatility: Evidence from panel data analysis, MRRA Working Paper, No. 100020.

Ruan, X. and Zhang, J. E. (2016). Investor attention and market microstructure, Economic Letters, 149, 125-130.

Talib, N. N. (2007). The Black Swan: The Impact of the Highly Improbable, New York, The Random House Publishing Group, Inc.

Onay, C., \& Ünal, G. (2012). Cointegration and extreme value analyses of Bovespa and the Istanbul stock exchange, Finance a Uver, 62(1), 66.

Vlastakis, N., and Markellos, R. N. (2012). Information demand and stock market volatility, Journal of Banking and Finance, 36(6), 1808-1821.

Wang, A. Y., and Young, M. (2020). Terrorist attacks and investor risk preference: Evidence from mutual fund flows, Journal of Financial Economics in press. 